\title{
ESTUDO DA DEGRADAÇÃO DO HERBICIDA ÁCIDO 2,4- DICLOROFENOXIACÉTICO (2,4-D) POR MEIO DA RADIAÇÃO GAMA DO COBALTO-60 EM SOLUÇÃO AQUOSA CONTENDO ÁCIDO HÚMICO
}

\author{
Sandro Xavier de Campos e Eny Maria Vieira* \\ Instituto de Química de São Carlos, Universidade de São Paulo, CP 780, 13560-970 São Carlos - SP
}

Recebido em 29/3/01; aceito em 19/12/01

\begin{abstract}
STUDY OF DEGRADATION OF THE HERBICIDE 2,4- DICHLOROPHENOXYACETIC ACID (2,4-D) BY GAMMA RADIATION FROM COBALTO- 60 IN AQUEOUS SOLUTION CONTAINING HUMIC ACID. The use of pesticides in agriculture presents some problems to ecosytems as a consequence of their remaining in the environment. Conventional methods for environmental decontamination sometimes just transfer these residues from one place to another. The use of gamma radiation from cobalt-60 to induce 2,4-D degradation in aqueous solution containing humic acid was studied. Results show that the herbicide is completely degraded after treatment with a $30 \mathrm{kGy}$ dose. There were decreases in the degradation of the 2,4-D when humic acid was added at all doses. Some radiolytic products are proposed. The 2,4-D radiolytic yields (G) from 2,4-D were calculated.
\end{abstract}

Keywords: 2,4-D; degradation; gamma radiation.

\section{INTRODUÇÃO}

A contaminação ambiental causada pelo uso crescente e indiscriminado de pesticidas tem gerado uma série de preocupações quanto ao comportamento destes compostos no ambiente.

Muitas operações convencionais de tratamento de resíduos de pesticidas muitas vezes apenas transferem estes resíduos de um ambiente para outro sem destruir o principio ativo.

A possibilidade de utilização da tecnologia nuclear e o emprego de radiações ionizantes (gama, elétrons e raios-x) como indutora da decomposição dos mais diversos poluentes orgânicos tem-se mostrado instrumento eficiente na descontaminação ambiental causada por esses agentes, além de mostrar ser também economicamente competitiva $^{1-5}$.Com esse intuito GRAY et al. ${ }^{6}$ comparam os custos da utilização de radiação gama e a incineração na degradação de dioxinas em solos, concluindo que a radiação, além de ter gerado melhores resultados de descontaminação, também mostrou ser economicamente atrativa. No Brasil o Instituto de Pesquisas Energéticas e Nucleares (IPEN) vem utilizando uma fonte de radiação piloto de elétrons acelerados em estudos de degradação dos mais diversos poluentes. SAMPA et al. ${ }^{7}$ utilizaram esta fonte para degradação de efluentes industriais que continham clorofórmio, benzeno e tolueno, entre outros poluentes, além de estimar os custos para a degradação. Os autores verificaram que a uma dose de $2 \mathrm{kGy}, 80 \%$ de todos os compostos foram degradados e que o custo seria em torno de US\$1,00/ $\mathrm{m}^{3}$, podendo ser minimizado se a técnica fosse utilizada com o aumento da aeração do meio ou ozônização. O uso de elétrons acelerados em conjunto com ozonização é considerado como sendo uma técnica muito eficiente em escala industrial, para degradação de poluentes biologicamente resistentes em meio aquoso ${ }^{8}$. No Canadá a empresa Nordion International Inc. ${ }^{9}$ busca aprovação para a instalação de um irradiador de cobalto-60 para tratamento de efluentes, mostrando que a técnica é competitiva economicamente e apresenta uma eficiência maior e mais ampla em relação a outras técnicas de degradação de contaminantes ambientais.
Devido a grande capacidade de penetração, a radiação gama pode ser utilizada na degradação de pesticidas nas mais diversas matrizes como, por exemplo, solos e substâncias húmicas ${ }^{10}$.

Neste trabalho buscou-se determinar os efeitos de diferentes doses de radiação gama na degradação do herbicida 2,4-D em meio aquoso como também verificar a influência do ácido húmico adicionado às amostras, estimando o valor radiolítico da degradação.

\section{PARTE EXPERIMENTAL}

\section{Fonte de radiação}

Na radiólise do herbicida 2,4-D foi utilizada uma fonte de radiação gama tipo JS 7500 com atividade de 920.000 Ci, fabricado pela empresa Nordion do Canadá, da Empresa Brasileira de Radiações, EMBRARAD em Cotia, SP, em atmosfera e temperatura ambiente.

\section{Ácido 2,4 diclorofenóxiacético (2,4-D)}

O herbicida $2,4-\mathrm{D}$, massa molar $=221,04$, com $98,5 \%$ de pureza, foi obtido junto a Laboratórios Dr. Ehrenstorfer, Alemanha. A Figura 1 apresenta a estrutura química do herbicida 2,4-D.

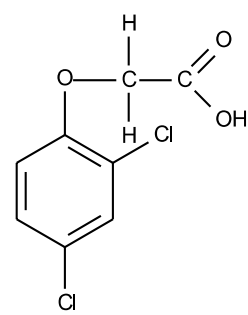

Figura 1. Estrutura química do herbicida 2,4-D

\section{Procedimento experimental}

Preparo das soluções a serem irradiadas

Foram preparadas soluções com e sem ácido húmico para serem irradiadas. As soluções sem ácido húmico foram preparadas dissol- 
vendo-se $25 \mathrm{mg}$ do herbicida em um litro de água Milli-Q. As soluções que foram irradiadas contendo ácido húmico foram preparadas dissolvendo-se $25 \mathrm{mg}$ do herbicida em um litro de água e adicionado ácido húmico extraído de solo, adquirido da Aldrich. A massa de ácido húmico foi adicionada em quantidade suficiente para obter-se uma concentração de $30 \mathrm{mg} \mathrm{L}^{-1}$ deste na solução.

\section{Radiólise do 2,4-D em solução aquosa com e sem ácido húmico}

As soluções aquosas do herbicida 2,4-D com e sem ácido húmico foram irradiadas em tubos de vidro de borosilicato com volume de 5 $\mathrm{mL}$. Os tubos foram selados utilizando maçarico (sob atmosfera de ar) e enviados para irradiação a doses que variaram de 0 a $30 \mathrm{kGy}$, todos à taxa de dose de $2,7 \mathrm{kGy} \mathrm{h}^{-1}$. Após as irradiações os tubos foram abertos e armazenados em frascos de vidro âmbar na geladeira até a realização das análises.

Quantificação do herbicida 2,4-D não degradado, por cromatografia líquida de alta eficiência (CLAE)

Para quantificar o 2,4-D não degradado em solução nas diferentes doses de radiação, foi feita uma curva analítica utilizando-se o método do padrão externo, nas concentrações de : 5, 10, 15, 20 e 25 $\mathrm{mg} \mathrm{L}^{-1}$. Para obtenção da curva analítica foi utilizado um cromatógrafo da Shimadzu LC - 9 com uma coluna RP - 18 HP (200 mm x 4,6 $\mathrm{mm} \times 10 \mu \mathrm{m})$, detector $\mathrm{UV}$ - vis com comprimento de onda fixo em $280 \mathrm{~nm}$, fase móvel com $40 \%$ acetronitrila $+60 \%$ água com $2 \%$ de ácido acético, operando no modo isocrático, vazão de $1 \mathrm{~mL} \mathrm{~min}^{-1} \mathrm{e}$ volume injetado de $20 \mu \mathrm{L}$. Estas condições foram selecionadas após estudos experimentais. Todas as amostras foram injetadas em triplicata.

Ánalise dos produtos de degradação do herbicida 2,4-D por Espectrometria de massas (ESI-MS) e espectrometria de massas tandem $(M S / M S)$

Depois de irradiadas e analisadas por CLAE, foram selecionadas amostras do 2,4-D para identificação dos produtos de degradação. As amostras foram analisadas por ESI-MS e MS/MS em um aparelho Micromass Quattro LC, equipado com triplo quadrupolo, do Departamento de Química da Universidade Federal de São Carlos (UFSCar). As amostras foram inseridas via injetor (loop $10 \mu \mathrm{L}$ ), utilizando-se como solvente $\mathrm{MeOH} / \mathrm{H}_{2} \mathrm{O}$ (70/30), bombeado por uma bomba Shimadzu LC-10 AD. O gás de nebulização e dessolvatação foi $\mathrm{N}_{2}$. Os experimentos de MS/MS foram feitos utilizando-se como gás de colisão argônio. A energia ótima de colisão utilizada foi de 10 e $30 \mathrm{eV}$. O programa para operação do equipamento, coleta e tratamento de dados foi Masslynx 3.1 (Micromass). Todas as amostras foram injetadas em triplicata.

\section{Valor radiolítico $(\mathbf{G})$}

O valor radiolítico $(G)$, é definido como o número de moléculas modificadas por energia aplicada, sendo que dentro do Sistema Internacional (SI) de unidades o valor de $\mathrm{G}$ é dado em $\mu \mathrm{mol} / \mathrm{J}^{8}$.

Este valor indica o grau de degradação de qualquer substância quando submetida a uma determinada dose de radiação. $\mathrm{O}$ valor radiolítico foi calculado para as soluções irradiadas do herbicida 2,4D a partir da regressão linear das concentrações do herbicida não degradado, em função das diferentes doses de radiação.

A taxa de degradação foi obtida por meio da inclinação da reta na regressão linear dos dados de concentração do herbicida não degradado em função da dose de radiação.

\section{RESULTADOS E DISCUSSÃO}

\section{Efeito da dose de radiação na degradação do herbicida 2,4-D}

As soluções do herbicida 2,4-D sem e com ácido húmico foram irradiadas nas doses de $1,5,10,20$ e $30 \mathrm{kGy}$ e taxa de dose de 2,7 $\mathrm{kGy} \mathrm{h}^{-1}$. A Figura 2 apresenta os resultados obtidos na forma de gráfico de barras.

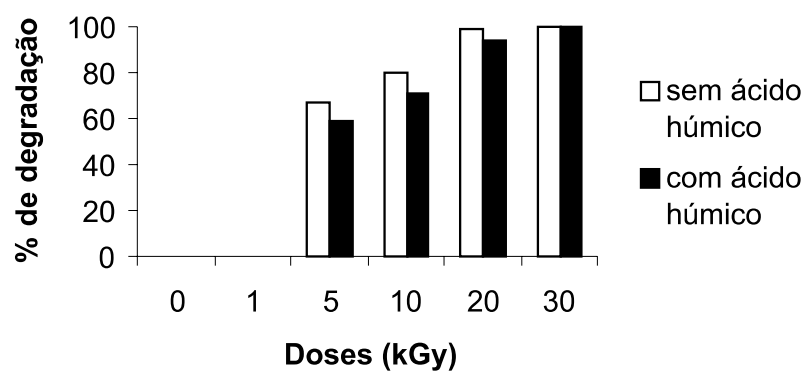

Figura 2. Porcentagem de degradação do herbicida 2,4-D padrão irradiado em água com e sem ácido húmico em relação à dose de radiação

Verifica-se que a degradação total do herbicida 2,4-D ocorreu a uma dose de 30 kGy e que as soluções irradiadas nas mesmas doses, apresentam uma porcentagem de degradação maior sem ácido húmico. Tal comportamento pode ser devido ao fato do 2,4- D ser adsorvido no ácido húmico. Desta forma o ácido húmico adicionado às soluções pode ter provocado um efeito de proteção não permitindo assim a ação da radiação gama sobre o herbicida.

Outra possibilidade é a de que as substâncias húmicas são consumidoras de radicais hidroxila $(\mathrm{OH})^{10}$ que, junto com os elétrons aquosos $\left(\mathrm{e}^{-}{ }_{\text {aq. }}\right)$, são as principais espécies formadas na radiólise gama da água. A literatura cita que o radical hidroxila $(\mathrm{OH})$ é a principal espécie oxidante na degradação fotocatalítica, fotoquímica e química da molécula do herbicida 2,4-D em solução aquosa ${ }^{11-14}$.

A Figura 3 apresenta cromatogramas representativos do 2,4-D não irradiado e após irradiado à dose de 10 kGy com e sem ácido húmico.

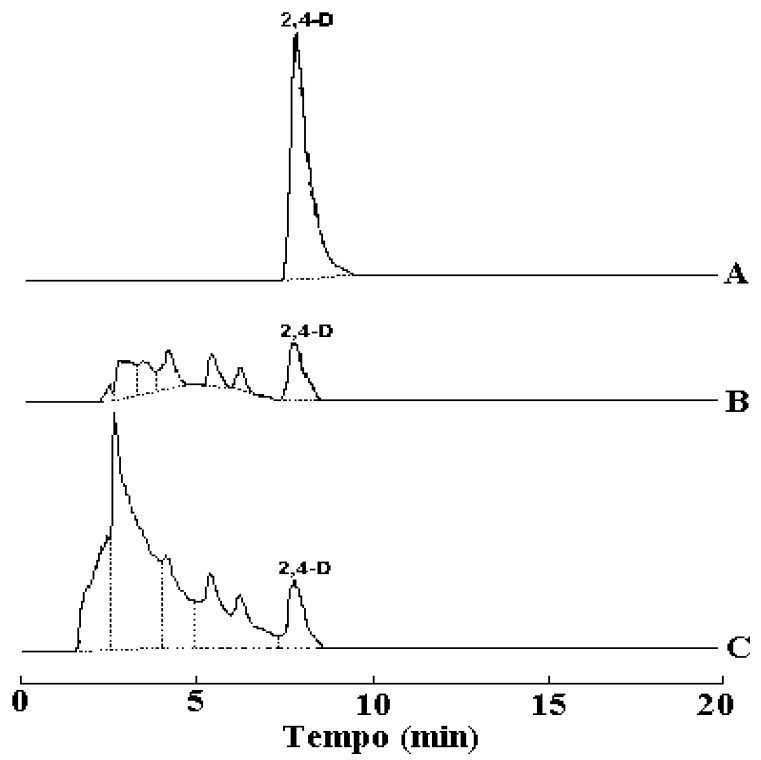

Figura 3. Cromatogramas obtidos por CLAE para o herbicida 2,4-D: A) herbicida 2,4-D em água não irradiado; B) herbicida 2,4-D em água irradiado a dose de $10 k G y$ à taxa de dose de $2,7 k G y h^{-1}$; C) herbicida 2,4$D$ em água contendo ácido húmico irradiado a dose de $10 k G y$ à taxa de dose de 2,7 kGy $h^{-1}$ 

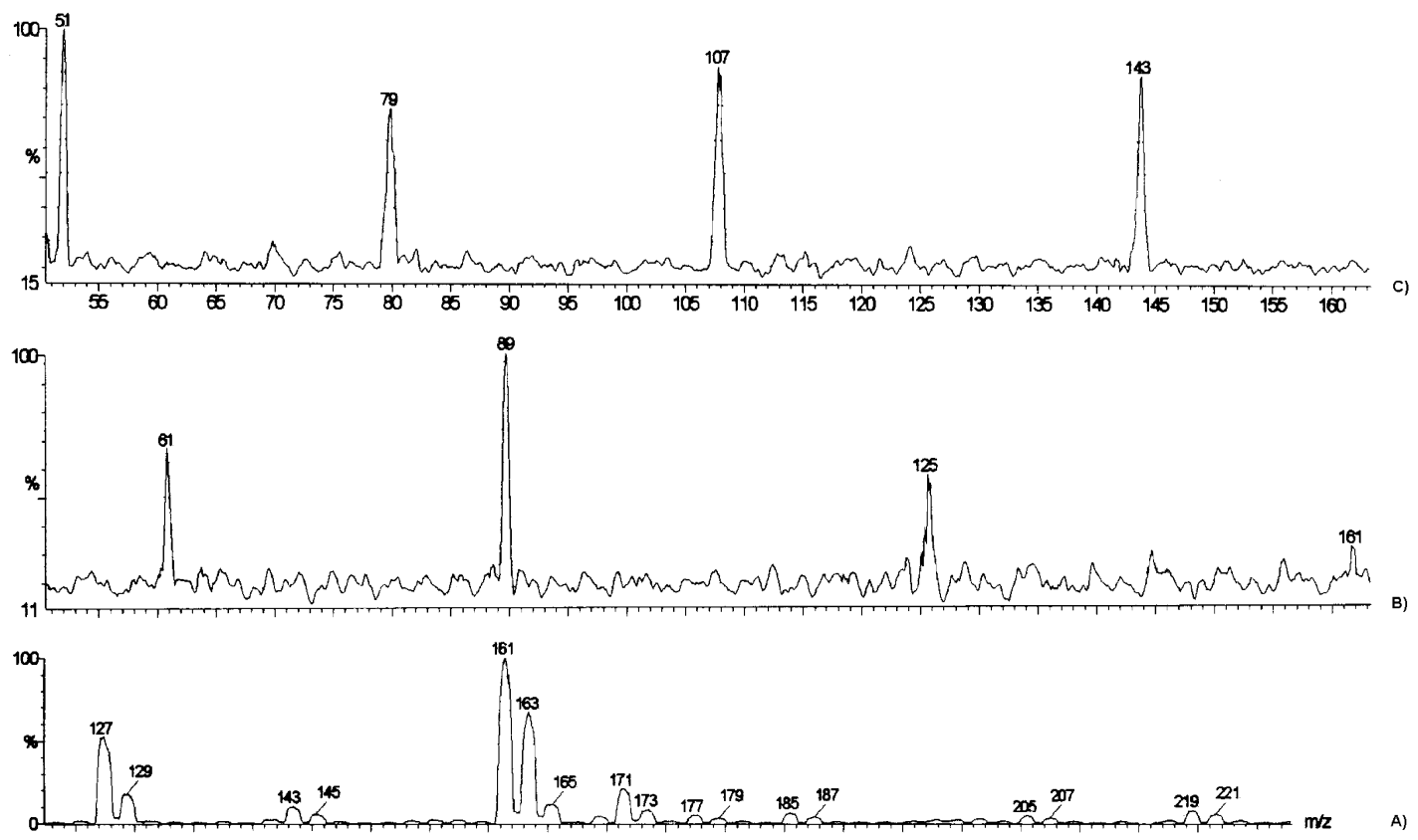

Figura 4. Espectros de ESI-MS e MS/MS do herbicida 2,4-D irradiado em água à dose de 20 kGy e à taxa de dose de 2,7 kGy $h^{-1}:$ A) ESI-MS; B) MS/MS do ion $\mathrm{m} / \mathrm{z} 161$, energia de colisão $=30 \mathrm{eV} ; C) M S / M S$ do íon $\mathrm{m} / \mathrm{z} 143$, energia de colisão $=30 \mathrm{eV}$

\section{Identificação dos produtos da degradação radiolítica do herbicida 2,4-D por (ESI/MS) e (MS/MS)}

$\mathrm{Na}$ tentativa de identificar alguns produtos provenientes da degradação radiolítica do herbicida 2,4-D foi selecionada a amostra irradiada a 20 kGy sem ácido húmico.

A Figura 4 apresenta o espectro de massas obtido por ESI-MS e os espectros MS/MS para os íons $\mathrm{m} / \mathrm{z}, 161$ e 143, com energia de colisão de $30 \mathrm{eV}$, para o herbicida 2,4-D irradiado em água à dose de 20 kGy sem ácido húmico à taxa de dose de $2,7 \mathrm{kGy} \mathrm{h}^{-1}$.

O íon $\mathrm{m} / z, 161$ foi selecionado por apresentar a massa molar igual a do 2,4 - diclorofenol. O 2,4-diclorofenol é um produto formado em maior abundância pela degradação microbiológica, oxidação eletroquímica e fotocatalítica do 2,4-D ${ }^{11,13,15}$. O íon $\mathrm{m} / z, 143$ foi selecionado por apresentar massa molar igual a do composto conhecido como clorohidroquinona, composto esse citado na literatura como sendo um dos produtos intermediários de outros métodos de degradação, como oxidação eletroquímica, fotodegradação e degradação fotocatalítica do $2,4-\mathrm{D}^{11-13}$.

O mecanismo de fragmentação proposto para o íon 161 é pela perda do grupo $\mathrm{HCl}$ com a formação do íon $\mathrm{m} / \mathrm{z} 125$, ocorrendo posteriormente a perda de outra molécula de $\mathrm{HCl}$ formando o íon $\mathrm{m} /$ $z 89$ e em seguida a perda do grupo CO formando o íon $\mathrm{m} / z$ 61. Para o íon $\mathrm{m} / z, 143$ o mecanismo proposto inicia-se pela perda do grupo $\mathrm{HCl}$ com a formação do íon $\mathrm{m} / z 107$, ocorrendo posteriormente a perda de uma molécula de CO formando o íon $\mathrm{m} / \mathrm{z} 79$ e em seguida a perda de outra molécula de CO formando o íon $\mathrm{m} / \mathrm{z} 51$. A Figura 5 apresenta as estruturas químicas do 2,4-diclorofenol e do clorohidroquinona.

Por meio destes resultados observa-se que os produtos intermediários formados na degradação radiolítica do 2,4-D podem ser bastantes tóxicos, como é o caso do 2,4 diclorofenol, que é um pesticida de difícil degradação da classe dos clorofenóis. Entretanto cabe salientar que, depois de uma dose de radiação de $30 \mathrm{kGy}$, o pico referente ao 2,4-D desapareceu e também houve uma significativa diminui-<smiles>Oc1ccc(Cl)cc1Cl</smiles>

A)<smiles>Oc1ccc(O)c(Cl)c1</smiles>

B)
Figura 5. Estruturas químicas: A) 2,4-diclorofenol, B) clorohidroquinona

ção dos picos referentes aos produtos intermediários de degradação com o desaparecimento da maioria deles. Desta forma, não apenas o 2,4-D é dependente da dose de radiação como também seus produtos de degradação.

\section{Valor radiolítico da degradação do herbicida 2,4-D}

Foram calculados os valores radiolíticos para a degradação do herbicida 2,4-D irradiado em meio aquoso com e sem ácido húmico, nas diferentes doses de radiação. Para calcular os valores radiolíticos da degradação do 2,4-D foi necessário transformar as concentrações de $\mathrm{mg} \mathrm{L}^{-1}$ para mol L-1.

A Tabela 1 apresenta as concentrações do herbicida 2,4-D não degradado, irradiado com e sem ácido húmico em relação as diferentes doses de radiação.

Com os dados da Tabela 1 calculou-se a taxa de degradação em mol L $\mathrm{kGy}^{-1}$. Para as soluções sem ácido húmico a taxa de degradação foi de $8,44 \times 10^{-6} \mathrm{~mol} \mathrm{~L}^{-1} \mathrm{kGy}^{-1}$, e o valor radiolítico, $\mathrm{G}=$ $0,0084 \mu \mathrm{mol} / \mathrm{J}$. Para as soluções com ácido húmico a taxa de degradação foi de $5,4 \times 10^{-6} \mathrm{~mol} \mathrm{~L}^{-1} \mathrm{kGy}^{-1}$ e o valor radiolítico, $\mathrm{G}=$ $0,0054 \mu \mathrm{mol} / \mathrm{J}$.

Os valores radiolíticos encontrados para o herbicida 2,4-D irradiado em água sem ácido húmico, foram maiores do que o irradiado 
Tabela 1. Concentração do herbicida 2,4-D não degradado, irradiado em água com e sem ácido húmico, em função da dose de radiação

\begin{tabular}{ccc}
\hline $\begin{array}{c}\text { Doses } \\
(\mathrm{kGy})\end{array}$ & $\begin{array}{c}\text { Concentração do 2,4-D } \\
\text { não degradado } \\
\left(\text { mol L }^{-1} \times 10^{-4}\right) \\
\text { sem ácido húmico }\end{array}$ & $\begin{array}{c}\text { Concentração do 2,4-D } \\
\text { não degradado } \\
\left(\text { mol L }^{-1} \times 10^{-4}\right) \\
\text { com ácido húmico }\end{array}$ \\
\hline 0 & $1,10 \pm 0,10$ & $1,10 \pm 0,15$ \\
1 & $1,10 \pm 0,15$ & $1,10 \pm 0,10$ \\
5 & $0,30 \pm 0,01$ & $0,40 \pm 0,01$ \\
10 & $0,20 \pm 0,02$ & $0,30 \pm 0,01$ \\
20 & $0,010 \pm 0,001$ & $0,060 \pm 0,002$ \\
30 & 0 & 0 \\
\hline
\end{tabular}

com ácido húmico, mostrando desta forma que, um número maior de moléculas do herbicida são degradadas para as soluções que foram irradiadas sem ácido húmico, comprovando assim sua influência na degradação do 2,4-D. Assim pode-se concluir que a radiação gama pode ser uma técnica eficiente na degradação do herbicida 2,4$\mathrm{D}$ e que quanto maior a dose de radiação maior foi a degradação do 2,4-D como também, seus produtos intermediários de degradação. $\mathrm{O}$ ácido húmico adicionado às soluções teve influência diminuindo o efeito da dose de radiação na degradação do herbicida em estudo.

\section{AGRADECIMENTOS}

Os autores agradecem a Empresa Brasileira de RadiaçõesEMBRARAD pela irradiação das amostras e ao CNPq pelo auxílio recebido na forma de bolsa de mestrado.

\section{REFERÊNCIAS}

1. Swinwood, J. F.; Fraser, F. M.; Radiat. Phys. Chem. 1995, 46, 1147.

2. Sawai, T.; Sekiguchi, M.; Shimokawa, T.; Radiat. Phys. Chem. 1993, 42, 723.

3. Icre, P.; Facorat, C.; Rocquigny, H.; Darbord, J. C.; Radiat. Phys. Chem. $\mathbf{1 9 9 5}, 46,1099$.

4. Getoff, N.; Bekbölet, M.; Radiat. Phys. Chem. 1999, 56, 333.

5. Drzewicz, P.; Panta, P.; Gluszewski, W.; Trojanowicz, M.; J. Radioanal. Nucl. Chem. 1999, 242, 601.

6. Gray, A. K.; Hilarides, R. J.; Radiat. Phys. Chem. 1995, 46, 1081.

7. Sampa, M. H. O.; Del Mastro, N. L.; Borrely, S. I.; Radiat. Phys. Chem. 1998, $52,333$.

8. Getoff, N.; Radiat. Phys. Chem. 1999, 54, 377.

9. Swinwood, J. F.; Fraser, F. M.; Radiat. Phys. Chem. 1995, 46, 1147.

10. Leitner, N. K. V.; Berger, P.; Gehringer, P.; Radiat. Phys. Chem. 1999, 55, 317.

11. Djebbar, K .; Sehili, T.; Pestic. Sci. 1998, 54, 269.

12. Trillas, M.; Peral, J.; Doménech, X.; Appl. Catal., B 1995, 5, 377.

13. Brillas, E; Calpe, J. C; Casado, J.; Water Res. 2000, 34, 2253.

14. Pignatello, J. J.; Environ. Sci. Technol. 1992, 26, 944.

15. Daugierty, D. D.; Karel, S. F.; Appl. Environ. Microbiol. 1994, 42, 3261. 